\title{
REDES DE FRANQUIA BRASILEIRAS INTERNACIONALIZADAS: EVOLUÇÃO DO MÉTODO DE ENTRADA NO EXTERIOR
}

\section{RESUMO}

Este artigo analisa os métodos de entrada das franquias brasileiras quando optam por se instalar fora do Brasil. Tendo como base um estudo multicasos, foram realizadas entrevistas presenciais em $2012 \mathrm{com} 21$ redes de franquias internacionalizadas. Entre os resultados, observou-se uma mudança de postura das redes de franquias brasileiras ao longo do tempo, com alteração no método de entrada em mercados internacionais. Destaca-se a intensificação da procura por parte de agentes externos dispostos a levar a marca para o exterior, fato que possibilitou que a estratégia predominante a partir de 2008 fosse franquear suas atividades diretamente a partir do Brasil.

Palavras-chave: Franchising; Franchising e Entrada no Mercado Estrangeiro; Internacionalização de Franquias; Métodos de Entrada no Exterior por Franquias.

\section{NETWORKS OF BRAZILIAN FRANCHISES INTERNATIONALIZED: EVOLUTION OF METHOD OF ENTRY ABROAD}

\begin{abstract}
This study examines the methods of entry of Brazilian franchises during the decision of internationalization of operations. Based on a multi-case study in 2012, face-to-face interviews were conducted with 21 internationalized franchise chains. The results suggest that Brazilian franchise chains have modified the method of entry into international markets in recent years. The predominant strategy from 2008 was franchising activities from Brazil. The role of the foreign agent has been essential to lead the Brazilian franching brand abroad.
\end{abstract}

Keywords: Franchising; Internationalization of Franchising; Franchising and foreign Market Entry; Input Methods for Franchises Abroad. 


\section{REDES DE FRANCOS INTERNACIONALIZADO BRASILEÑO: EVOLUCIÓN DEL MÉTODO DE ENTRADA EN EL EXTRANJERO}

\section{RESUMEN}

Este trabajo analiza los métodos de entrada de las franquicias brasileñas, cuando optan por asentarse fuera de Brasil. Basado en un estudio de casos múltiples, las entrevistas personales se realizaron en 2012 con 21 franquicias redes internacionalizadas. Entre los resultados, se observó un cambio en la postura de las redes de franquicias brasileñas a través del tiempo, con los cambios en el método de entrada en los mercados internacionales. Es de destacar el aumento de la demanda de dispuesto a tomar la marca en el exterior, lo que hizo posible la estrategia dominante a partir de 2008 fue las actividades de franquicia directamente de los agentes externos de Brasil.

Palabras clave: Franquicias; Franquicias y Entrada en el Mercado Extranjero; Internacionalización de Franquicias; Métodos de Entrada de Franquicias en el Extranjero.

\footnotetext{
${ }^{1}$ Mestre em Administração pelo Centro Universitário da Faculdade de Engenharia Industrial - FEI. Pesquisador da Universidade de São Paulo - USP. Brasil. E-mail: $\underline{\text { helder_aguiar@uol.com.br }}$

${ }^{2}$ Doutora em Política Científica e Tecnológica pela Universidade Estadual de Campinas - UNICAMP. Professora do Programa de Mestrado e Doutorado em Política Científica e Tecnológica do Instituto de Geociências da Universidade Estadual de Campinas - UNICAMP. Brasil. E-mail: flavia@ige.unicamp.br

${ }^{3}$ Doutor em Sociologia pela Universidade de São Paulo - USP. Professor da Faculdade de Engenharia Industrial - FEI. Brasil. E-mail: bernardes@fei.edu.br
} 


\section{INTRODUÇÃO}

O segmento das franquias nos países emergentes, desde os anos oitenta, tem se notabilizado pela velocidade e amplitude de crescimento continuado do seu mercado (Welch \& Alon, 2001). Neste cenário, o Brasil tem se consagrado como um importante player. Nas duas últimas décadas, um fator decisivo foi o ciclo expansivo dos investimentos experimentados nas incorporações de shoppings centers que impulsionaram consideravelmente a criação de novas pequenas e médias empresas (PMEs), principalmente no segmento de franquias (Dahab, 1996). Em 2012, segundo dados da Associação Brasileira de Franquias (ABF) (2013), o setor de franchising faturou 103,292 bilhões de reais no Brasil, com um total de 2.426 redes com 104.543 unidades, que são responsáveis pela geração de 940.887 empregos diretos.

O franchising brasileiro já não se limita apenas ao mercado nacional. Nos últimos anos, ainda que de forma gradual, o setor inaugura uma fase experimental nas iniciativas de internacionalização destas operações. Neste movimento, verifica-se um novo fluxo de ações para internacionalização, onde não somente empresas estrangeiras buscam o Brasil como mercado consumidor, mas também empresas brasileiras acessam novos mercados no ambiente internacional. A evolução e a diversificação das franquias brasileiras presentes no exterior foi digna de destaque. No período de apenas doze anos, ou seja, entre 2000-2012, o crescimento foi de $486 \%$. Este movimento em relação ao número de redes instaladas em outros países representou um salto significativo, de 15 para 88 marcas nacionais (ABF, 2012).

Considerando que as estratégias de internacionalização das empresas dos países do hemisfério sul como ações deliberadas em expansão, formalmente organizadas, são um fenômeno recente no mercado mundial (Oliveira Jr, 2010; Coelho, 2011), a performance do setor de franchising, que não possui a internacionalização como uma estratégia corrente (Aguiar, 2014), torna-se ainda mais notável.

No que tange às pesquisas acadêmicas envolvendo internacionalização de redes de franquias brasileiras, estas passaram a compor a agenda de interesses dos pesquisadores nacionais sobre tal temática. Como se trata de um campo de pesquisa emergente no Brasil, a maior parte destas pesquisas têm se pautado por abordagens de que privilegiam análises exploratórias. Embora estes estudos tenham sido criticados pelas limitações quanto o tamanho das suas amostragens, alguns contemplando 15 redes (Marques, 2006), 16 redes (FDC [Fundação Dom Cabral], 2012) e ou 20 redes (Rocha, Borini, Spers, Khauaja \& Camargo, 2012) é possível identificar contribuições para o avanço e a acumulação do conhecimento sobre a evolução do movimento de internacionalização do setor e do comportamento das franquias brasileiras com operações no exterior. Mesmo reconhecendo a contribuição de tais estudos, pode ser identificada ainda uma lacuna na pesquisa acadêmica sobre os métodos de entrada das franquias brasileiras em mercados internacionais, como as empresas desse segmento se organizam, preparam e como ocorre o seu envolvimento com os parceiros estrangeiros

É no âmbito deste debate que este artigo se insere, ampliando a compreensão acerca dos métodos de entrada das redes de franquias brasileiras no exterior.

"Método de entrada", neste caso, inclui a forma como uma franquia estrutura a sua saída para o exterior, o que pode ocorrer a partir de cinco principais configurações: instalando unidades próprias; com franqueados nos locais de destino (Franqueado Direto); com franqueados que possuem o direito de operar e comercializar o negócio de franquias em outras localidades (Máster Franquia); em associação com parceiros locais no país de destino (Joint Venture) e; instalando subsidiárias no exterior. Nesse sentido, comparativamente às demais pesquisas conduzidas sobre este tema, a principal contribuição deste artigo consiste em realizar um maior detalhamento acerca dos métodos de entrada das redes de franquias brasileiras no exterior.

Os estudos sobre métodos de entrada, em geral, têm se concentrado em redes norte- americanas e suas incursões em mercados externos (Doherty \& Alexander, 2004), não havendo estudos em profundidade tratando apenas sobre essa temática com foco nas redes brasileiras de franquia.

Sabe-se que as redes de franquias, quando operam fora de seu país de origem, estão sempre sujeitas a se deparar com trade-offs. Se as redes não operam com um parceiro local, podem estar sujeitas à falta de conhecimento dentro desse país; em contrapartida, elas podem exercer maior controle sobre toda a operação. No caso de operarem unidades próprias no país destino, o controle sobre as operações é total, porém o investimento para que se tenha uma operação internacional pode ser proibitivo. Outro ponto que pode ser destacado diz respeito ao retorno dos investimentos. Ter um máster franqueado pode ser uma opção de pouco investimento já que a rede só precisa treinar a equipe do operador internacional; o problema é que o retorno financeiro pode ser aquém do esperado, visto que esse parceiro tem um investimento que necessita ser remunerado (Sanghavi, 1991).

Considerando a diversidade de modos de entrada e de condicionantes de tais processos que se colocam como alternativa para as franquias quando estas decidem internacionalizar suas atividades, a questão que se coloca é: quais os métodos de entrada que as franquias brasileiras utilizaram quando iniciaram seu processo de internacionalização? 
Com a proposta de ampliar a reflexão sobre este tema, o objetivo deste artigo consiste em investigar os principais métodos de entrada das franquias brasileiras no exterior quando da sua primeira investida no mercado internacional.

São duas as contribuições esperadas com este estudo:

- para a academia, trata-se de proporcionar maior conhecimento sobre os métodos de entrada para internacionalização do setor franchising de países emergentes, visto que a maior parte ainda se concentra nos países desenvolvidos;

- para a iniciativa empresarial, trata-se de evidenciar os estágios percorridos e de identificar, de forma objetiva, os desafios a serem aprendidos e superados para a promoção de estratégias voltadas à internacionalização, além elucidar a escolha do modo de entrada da empresa. Desse modo, os empresários do setor de franquias, podem observar que controle e investimento podem ser variáveis inversamente proporcionais.

Para o alcance destes objetivos, foi elaborado um estudo com base em um método multicasos com uma amostra composta por 21 redes de franquias brasileiras com operações no exterior. A estratégia operacional da pesquisa envolveu a aplicação de questionários semiestruturados de modo presencial no mês de junho de 2012.

Este artigo encontra-se organizado em torno de quatro seções, além desta Introdução. A seção seguinte traz uma revisão de literatura sobre o tema franquias, com ênfase nos métodos de entrada de internacionalização. Em seguida, são discorridos os aspectos metodológicos que envolveram a coleta de dados em campo, seguida de uma seção de resultados.

Por fim, as considerações finais destacam a constatação de que as marcas nacionais cada vez mais têm atraído investidores dispostos a levá-las para outros países. As vantagens desta estratégia é que os parceiros acabam por amenizar as barreiras de entrada cabendo aos franqueadores, a partir da estrutura já existente no Brasil, controlar as atividades, tomar decisões e, eventualmente, promover ajustes no sistema.

\section{AS FRANQUIAS E OS MÉTODOS DE ENTRADA PARA INTERNACIONALIZAÇÃO}

\subsection{As franquias: conceito e dinâmica de mercado}

Por definição, o franchising é um negócio previamente formatado e testado (Dahab, 1996; Stanworth, \& Dandridge, 1994; Stanworth, Stanworth, Watson, Purdy \& Healeas 2004; Melo \& Andreassi,
2012). Para Stanworth e Dandridge (1994), franchising é um negócio que essencialmente consiste de uma organização ou empresa conhecida como a franqueadora, com um pacote de negócio testado em mercado, centrado em um produto ou serviço.

O sistema de franchising possibilitou, principalmente para algumas indústrias, o desenvolvimento de um canal de distribuição pelo qual se tem o controle, e onde pode-se verticalizar as estratégias como um todo, diferentemente do que acontece quando utilizam-se varejistas, distribuidores ou representantes para sua distribuição para o consumidor final. Como o sistema é regido por um contrato, ela, (a franqueadora) apesar de não ser a proprietária da unidade franqueada, é dona do conceito e pode, por força deste contrato, aplicar sanções e até mesmo romper o vínculo com o franqueado.

Sabendo que o negócio possui vantagens competitivas sustentáveis capazes de assegurar uma vida útil que possibilite haver retorno sobre $o$ investimento, uma competência básica que o franqueador necessita é a capacidade de saber recrutar um parceiro certo e compatível com seu negócio (Hoy \& Shane, 1998). Essa atitude estratégica pode ser explicada pela teoria da escassez de recursos, nome proposto por Carney e Gedajlovic (1991), originalmente elaborada por Oxenfeldt e Kelly (1969). Trata-se de uma teoria que busca explicar a existência do sistema de franchising e, portanto, se mostra bastante norteadora dos estudos conduzidos neste campo. Na perspectiva desta abordagem, franquiar permite acessar recursos de ordem financeira e gerencial, fato este que possibilita obter expansão acelerada (Oxenfeldt \& Kelly, 1969). Isso ocorre tanto na dimensão nível nacional quanto internacional, podendo ser um franqueado, um máster franqueado ou uma outra empresa que se associará por meio de uma joint venture. A sobrevivência do modelo depende muito desse relacionamento.

$\mathrm{Na}$ teoria da agência, elaborada por Jensen e Meckling (1976), o franqueado no sistema de franquia pode ser considerado um sócio. Muitas vezes pode parecer que sua figura assemelhasse a de um gerente, mas não se deve esquecer que ele é um empreendedor que recorre a alternativa do franchising para contar com uma marca estabelecida, um know-how e mesmo uma facilidade de financiamento (Combs, Ketchen, Shook, \& Short, 2011). A teoria da agência ajuda a entender o porquê de as empresas buscarem um parceiro/proprietário. Por outro lado, estar associado a uma marca já conceituada faz com que desperte nos parceiros uma imagem diferenciada deles mesmos (Sardy \& Alon, 2007).

Não é apenas o consumidor que deve ser percebido como fator responsável pelos lucros. O distribuidor, no caso o agente que se associa ao franqueador, não é apenas um agente passivo e facilitador no processo de vendas ao consumidor final (Benoun \& Héliès-Hassid, 2004), ele também é um 
Redes de Franquia Brasileiras Internacionalizadas: Evolução do Método de Entrada no Exterior

cliente importante, cujo negócio deve ser compreendido (Randall, 1994).

Assim, para o setor de franchising sobreviver à dinâmica do mercado, terá que mudar e adaptar-se frequentemente, o que exigirá sinergia entre as estratégias do franqueador e de seus parceiros, em razão da possibilidade de aproveitamento das experiências locais destes últimos (Toledo \& Proença, 2005).

\subsection{Métodos de entrada de franquias em mercados internacionais}

Segundo Doherty e Alexander (2004), a maior parte dos trabalhos desenvolvidos para o estudo de franquias se concentra nos Estados Unidos (EUA), e está baseado em casos que ocorreram com empresas americanas de franchising. Sendo o mercado americano o maior e mais desenvolvido no ramo do franchising é de se esperar que também este seja o mais estudado. Segundo dados da World Franchise Council (WFC) (2012), o mercado americano contava com 825 mil unidades franqueadas somente em seu mercado nacional, sendo assim o maior mercado deste setor. A intenção de internacionalizar as operações das empresas de franchising, criadas na sua origem em bases nacionais para mercados altamente competitivos, a exemplo dos EUA ou mercados nascentes como América Latina, Ásia e África, tem se tornando uma tendência recorrente neste setor (Alon, 2006).

Os níveis de controle e investimento da internacionalização de franquias estão intimamente ligados aos seus métodos de entrada em mercados estrangeiros. Segundo estudos conduzidos por uma diversidade de pesquisadores (Quinn, 1998; Peterson \& Welch, 1999: Silva, Mendes \& Gomes, 2002; Mendelsohn, 1994; Marques, 2006; Melo, 2012; Welsh, Alon \& Falbe, 2006; Quinn \& Doherty, 2000; Baena Graciá \& Cerviño, 2009), são cinco os principais métodos de entrada que uma franquia pode optar ao decidir por se internacionalizar:(i). Unidade Própria; (ii) Franqueado Direto; (iii) Máster Franquia; (iv) Joint Venture e; (v) Franqueado a partir de Subsidiária.

Cada um destes métodos inclui as seguintes determinações e especificidades, da forma como segue:

Unidade Própria: o próprio franqueador opera uma unidade ou unidades fora de seu país. Essa pode ser a opção encontrada pelas redes para as possíveis adaptações que se façam necessárias antes de iniciar o processo de venda de franquias (Quinn, 1998). A empresa opera e conhece o mercado em profundidade, testa as possíveis alterações e assim pode oferecer a seus franqueados a essência do franchising, um negócio previamente formatado e testado. Neste método, a rede dispende de uma grande carga de recursos, visto que ela é responsável por toda a operação, desde os custos com a prospecção do local até a escolha de pessoal que, por ventura, venha a trabalhar na unidade. A contrapartida para a rede é o controle total da operação. Sem parceiro, associado ou qualquer barreira entre a empresa e a operação, toda a cultura pode ser passada sem interferência. Autores, tais como Combs e Ketchen, (1999) e Alon (2001) argumentam que esse método não é dos mais comuns, pois não tendo parceiros, por um lado, a rede não se beneficia de rápida expansão a custo baixo que é um preceito do sistema de franchising; por outro, pode ser o mais lucrativo.

Franqueado Direto: trata-se do método mais utilizado quando as franquias iniciam esta estratégia de internacionalização. A proximidade cultural e geográfica nas primeiras experiências de internacionalização de franquias explicava essa opção, o que é reforçado pelo exemplo das redes de franquias norte-americanas que se expandiam para o Canadá e para o México. Nesta opção, verifica-se um baixo investimento quando o franqueador necessita que uma equipe visite o local, faça um levantamento e adapte a operação para o país hospedeiro. Configura-se como uma estratégia que demanda baixa investimento na comparação com outros métodos de entrada. Além disso, o controle da operação sem uma consultoria constante no local pode afetar o controle sobre toda a operação. Para Alon (2006), esse método é mais comum quando os destinos são culturalmente próximos, o que foi comprovado em alguns estudos sobre redes americanas que operavam no Canadá, Reino Unido e Austrália (Welch, 1989; Burton \& Cross, 1995).

Master Franquia: na opção máster franquia um operador local fica responsável por vender e controlar as operações em um determinado território. As redes de franquias americanas começaram a optar por este método de entrada preferencialmente a partir de 1989. Esse período reflete uma nova estratégia de internacionalização nas redes norte- americanas, que nos anos 1990 iniciaram uma maior expansão em mercados que não eram culturalmente próximos, como os mercados da Ásia, Europa Central, Leste Europeu e países emergentes pelo mundo (Welsh \& Alon, 2001; Alon \& Welsh, 2001). Esse movimento em parte se dá porque em mercados culturalmente distantes um parceiro com expertise local, principalmente nas leis e obtenção de crédito, pode ser vital para a rede (Sashi \& Karuppur, 2002). Como com a máster franquia o franqueador despende de poucos recursos, esta pode ser a maneira mais rápida da rede crescer para fora de suas fronteiras. Estudos conduzidos no Brasil, tais como os de Borini, Rocha \& Spers (2012) e Marques (2006), apontam que esse é o método mais utilizado pelas redes brasileiras. A contrapartida é que o sistema todo está totalmente ligado e dependente do parceiro local. A escolha do parceiro torna-se assim um desafio para a empresa. Além de despender de recursos ele deve estar totalmente alinhado com a franqueadora. Com base no estudo de caso relatado por Melo, Andreassi e Oliveira 
(2010) sobre uma rede brasileira de fast-food e um máster franqueado no México, fica claro que uma escolha errada só traz desperdício de tempo e capital, além de a marca ficar sujeita a uma avaliação negativa para novas investidas neste país (Quinn \& Doherty, 2000).

Joint Venture: no franchising, o joint venture é utilizado em países onde a legislação obriga a associação com um parceiro local e em mercados culturalmente muito distantes. Os custos são reduzidos quando comparados a uma operação com subsidiária ou unidade própria, mas são mais elevados que na máster franquia ou no franquiado direto. Para a realização de joint ventures ou alianças estratégicas entre o franqueador e um parceiro local, ambas as partes contribuem com recursos financeiros e humanos na introdução da rede de franquias no novo mercado. Além disso, há o benefício do parceiro local ter o conhecimento dos mecanismos deste novo mercado e conhecimento, por exemplo, da concorrência local (Barkema \& Vermeulen, 1998). Os níveis de risco, controle e benefícios são diretamente proporcionais ao nível de investimento realizado pela empresa no momento da incorporação da joint venture. No entanto, a joint venture também pode causar problemas por requerem a cooperação com parceiros locais cujos interesses podem, em algum momento, não coincidirem com os da empresa que pretende entrar no mercado (Chang \& Rosenzweig, 2001).
Franqueado a partir de uma subsidiária: neste método a empresa possui uma operação no país destino que é responsável pela venda e controle das franquias. Há autores que consideram este modo como um franqueado direto (Baena Graciá \& Cerviño, 2009; Quinn \&Alexander, 2002) e outros que consideram um método a parte (Rocha et al., 2012). Quando a empresa se utiliza deste método, uma nova unidade de negócios completa acaba sendo formada. A proximidade com o franqueado é muito maior. Por estar presente no país e, supostamente, desempenhar todos os papéis inerentes a um franqueador local a rede acompanha de perto o desenvolvimento do negócio e se beneficia da troca de experiência entre os agentes da franquia. Os custos e o investimento neste método devem ser levados em conta, pois, dependendo do número de unidades, pode tornar-se inviável. Manter todo um sistema para a venda e controle com baixo resultado financeiro pode não ser viável em um primeiro momento e pode até mesmo acarretar o fechamento da operação no país de destino.

Entre estas várias opções, a empresa de franquia pode escolher o método de entrada considerando fatores estratégicos (Sanghavi, 1991) que abrangem: tempo de retorno do investimento; nível de controle sobre a operação internacional; recursos disponíveis; e o quanto será flexível o franqueador com seus parceiros no exterior.
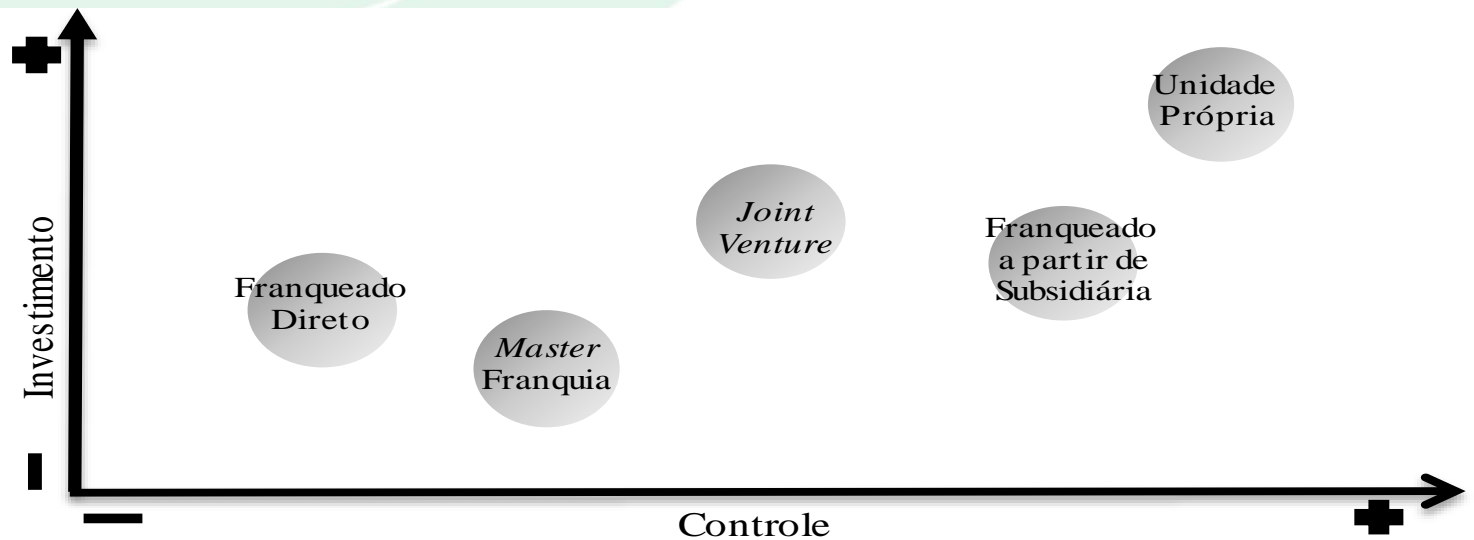

Figura 1 - Relação investimento versus controle Fonte: Elaborado pelos autores.

Na Figura 1 há uma representação gráfica relacionando investimento versus controle. A proximidade em relação ao eixo $\mathrm{X}$ explica se a forma empregada é mais ou menos propicia ao controle e no eixo Y se a opção de investimento é maior ou menor.

$\mathrm{O}$ método de entrada internacional pode ser, segundo Petersen e Welch (2002), reflexo da experiência no mercado doméstico. Assim como ampliar a rede dentro de seu mercado natal requer cuidado e eficiência, de modo que não se perca valores dentro da rede, tais como a cultura organizacional e ativos intangíveis, também na internacionalização essa expansão e o modo como ela se dá é fator determinante do sucesso do processo. 
Redes de Franquia Brasileiras Internacionalizadas: Evolução do Método de Entrada no Exterior

Tabela 1 - Métodos de entrada em mercados internacionais por franquias

\begin{tabular}{|c|c|c|c|}
\hline MÉTODO & INDICAÇÃO & ASPECTOS POSITIVOS & ASPECTOS NEGATIVOS \\
\hline $\begin{array}{l}\text { Unidade } \\
\text { Própria } \\
\end{array}$ & - Teste e verificação da estratégia. & - Controle total. & - Alto investimento. \\
\hline $\begin{array}{l}\text { Franqueado } \\
\text { Direto }\end{array}$ & $\begin{array}{l}\text { - Inicio da operação com poucas } \\
\text { unidades. Geralmente países próximos } \\
\text { cultural e geograficamente. }\end{array}$ & - Pouco investimento. & - Dificuldade de controle. \\
\hline $\begin{array}{c}\text { Master } \\
\text { Franquia }\end{array}$ & $\begin{array}{l}\text { - Necessidade de um parceiro com } \\
\text { conhecimento no mercado local }\end{array}$ & $\begin{array}{l}\text { - Parceiros que conhecem a } \\
\text { burocracia dos países destino. }\end{array}$ & $\begin{array}{l}\text { - Alta dependência do máster } \\
\text { franqueado. }\end{array}$ \\
\hline Joint Venture & $\begin{array}{l}\text { - Alguns países exigem a participação } \\
\text { de um parceiro local. }\end{array}$ & - Divisão de custos. & $\begin{array}{l}\text { - A legislação do país tende a } \\
\text { proteger o parceiro local. }\end{array}$ \\
\hline $\begin{array}{c}\text { Franqueado a } \\
\text { partir de } \\
\text { Subsidiária } \\
\end{array}$ & $\begin{array}{l}\text { - Desenvolver um sistema para a } \\
\text { abertura de unidades no exterior. Utiliza } \\
\text { capital próprio para gestão. }\end{array}$ & $\begin{array}{l}\text { - Controle dos franqueados. } \\
\text { A “empresa" está presente no } \\
\text { país. }\end{array}$ & $\begin{array}{l}\text { - Estrutura não cobre seus } \\
\text { custos. }\end{array}$ \\
\hline
\end{tabular}

Fonte: Adaptado de Melo, 2012

Segundo Quinn e Doherty (2000), uma estratégia errada pode acarretar a deterioração da imagem e da marca no país de destino. Ademais, pode também comprometer a saúde financeira da rede de franquias, frustrando futuros planos de expansão, ou até mesmo o fim de um projeto de internacionalização.

Sob esta perspectiva, a Tabela 1 concentra os esforços em agregar em uma única representação, os cinco métodos de entrada no exterior, com menção às suas particularidades, incluindo aspectos positivos e negativos da operação.

\section{PLANO ANALÍtico E OPERACIONAL DA PESQUISA}

O método de pesquisa adotado nesta pesquisa consistiu na elaboração de um estudo qualitativo com base na aplicação de entrevistas presenciais. A preocupação em estudos qualitativos é responder a pergunta "O que está acontecendo aqui?" (Gibbs, 2009), e esta é exatamente a proposta deste estudo. O foco principal é fornecer uma descrição dos processos estudados, enfatizando a estratégia adotada pelas empresas.
A análise teórica sobre o assunto: o que é importante quando as empresas buscam um novo país (Kedia; Ackerman \& Justis, 1995); motivadores da internacionalização de franquias nacionais (Khauaja, 2009; Marques; Merlo \& Lucchesi, 2005; Marques, Merlo \& Nagano, 2009); visão ampla dos estudos a respeito de internacionalização de franquias. (Melo \& Andreassi, 2012; Melo, 2012; Melo, Andreassi \& Oliveira, 2012); comparação com estudos realizados em mercados culturalmente próximos, no caso a Península Ibérica (Pedro; Filipe \& Reis, 2008); estudos realizados com o aval e apoio da $\mathrm{ABF}$ por meio das ESPM (Rocha, Borini \& Spers, 2010; Rocha et al., 2012); analisar a expansão do franchising como uma estratégia de crescimento para a pequena empresa (Stanworth, Stanworth \& Watson, 2004); pontos importantes quando as empresas se internacionalizam (Kedia, Ackerman \& Justis, 1995); e os principais métodos de entrada que uma franquia pode optar ao decidir por se internacionalizar (Quinn, 1998; Peterson \& Welch, 1999: Silva, Mendes \& Gomes, 2002; Mendelsohn, 1994; Marques, 2006; Melo, 2012; Welsh, Alon \& Falbe, 2006; Quinn \& Doherty, 2000; Baena Graciá \& Cerviño, 2009), possibilitou que fosse elaborado o questionário para a coleta de dados. 


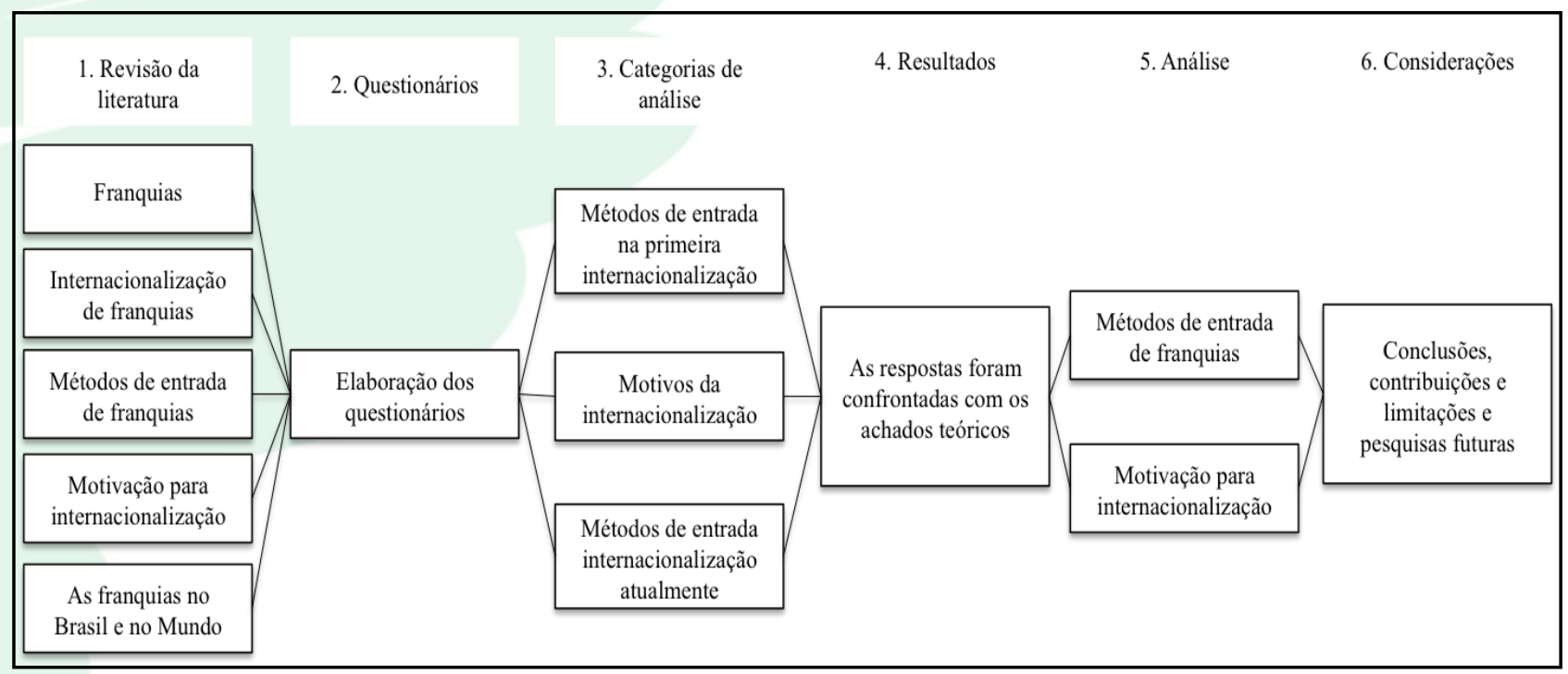

Figura 2 - Fluxo Metodológico

Fonte: Elaborado pelos autores.

Em seguida, as categorias de análise, o método de entrada na primeira internacionalização; os motivos da internacionalização; e métodos de entrada na internacionalização atualmente foram confrontados com os achados teóricos. A Figura 2 apresenta o fluxo metodológico da pesquisa.
Para a escolha e definição da população do estudo foram adotados determinados critérios, priorizando o fato de a empresa ser tanto brasileira (capital nacional) quanto ser uma franqueadora internacionalizada, conforme Figura 3.

\begin{tabular}{|c|}
\hline FOCO DA PESQUISA: EMPRESA BRASILEIRA, FRANQUEADORA E \\
INTERNACIONALIZADA \\
\hline 1.Internacionalizada \\
\hline 2.Franqueadora \\
\hline 3.Com sede no Brasil \\
\hline 4.Criada no Brasil \\
\hline
\end{tabular}

Figura 3 - Critérios para escolha da amostra

Fonte: Elaborado pelos autores.

Para a seleção das empresas alvo da pesquisa, foi utilizado o banco de dados da $\mathrm{ABF}$, que traz um conjunto de informações sobre as empresas brasileiras associadas, tais como possuir operação no exterior; número de unidades internacionais; países de destino destas unidades. Em simultâneo, foi realizada uma avaliação acerca das franquias que estariam presentes na ABF Franchising Expo 2012. Trata-se da principal feira de franquias da América Latina que é realizada há 21 anos (ABF, 2012). Todos os setores atuantes do ramo do franchising no país são representados nesta feira. Entre os participantes, foi identificada a presença de 22 franquias nacionais que possuem unidades no exterior. Deste total, 21 franquias concordaram em participar desta pesquisa, tendo sido entrevistadas pessoas que atuam no comando gerencial destas franquiadoras e com conhecimento sobre as atividades internacionalizadas.
Esta amostra contemplou $24 \%$ de todas as empresas do setor de franchising que possuem atividades internacionais, ou seja, 21 empresas de um total de 88 registradas no banco de dados da ABF. Essas 21 empresas possuem $34,5 \%$ de todas as unidades no exterior, com um total de 237 unidades de um universo de 690 no ano de 2012.

Ademais, trata-se de uma amostra bastante diversa em termos setoriais, tendo sido contemplados representantes de cinco setores de atividade, a saber: Educação, seis empresas representando $28,5 \%$ da amostra; Alimentação, cinco empresas representando $23,8 \%$ da amostra; Serviços, cinco empresas representando $23,8 \%$ da amostra; Vestuário, três empresas representando $14,3 \%$ da amostra e Acessórios, duas empresas representando 9,5\% da amostra. 


\section{RESULTADOS DA PESQUISA}

Esta seção explora os resultados da pesquisa acerca dos modos de internacionalização de franquias brasileiras contempladas nesta amostra da pesquisa.

A Tabela 2 é uma síntese das informações sobre a amostra da pesquisa e inclui: o ano que a rede iniciou suas atividades no exterior; o primeiro país onde a rede se instalou; e o método de entrada utilizado quando da primeira internacionalização da empresa.

Especificamente em relação aos modos de entrada, a Figura 4 traz os resultados quanto ao primeiro país escolhido para operar no exterior, sendo o mercado americano o mais acessado pelas empresas, seguido de Angola. Uma ressalva deve ser feita quanto a esse resultado. Além das oportunidades inerentes do mercado angolano e a sua proximidade cultural, também deve-se considerar que essas empresas foram procuradas por representantes dos governos deste país, inclusive com apoio logístico e legal, para que lá se estabelecessem. Já a ação governamental brasileira ficou restrita a duas redes, ambas assistidas pela Agência Brasileira de Promoção de Exportações e Investimentos (Apex-Brasil).

Tabela 2 - Síntese da amostra de franquias internacionalizadas (2012)

\begin{tabular}{|l|l|l|l|}
\hline \multicolumn{1}{|c|}{ SEGMENTO } & EXTERIOR & PRIMEIRO PAÍS & $\begin{array}{c}\text { MÉTODO DE ENTRADA DA } \\
\text { PRIMEIRA UNIDADE }\end{array}$ \\
\hline Educação & 1985 & Argentina & Unidade Própria \\
\hline Educação & 1989 & Portugal & Unidade Própria \\
\hline Educação & 1991 & Estados Unidos & Máster Franquia \\
\hline Educação & 2002 & Estados Unidos & Máster Franquia \\
\hline Serviços & 2002 & Angola & Franqueado Direto \\
\hline Alimentação & 2004 & México & Máster Franquia \\
\hline Vestuário & 2004 & Peru & Máster Franquia \\
\hline Educação & 2006 & Angola & Máster Franquia \\
\hline Serviços & 2006 & Venezuela & Franqueado Direto \\
\hline Acessórios & 2007 & Portugal & \\
\hline Acessórios & 2007 & Estados Unidos & Unidade Própria \\
\hline Vestuário & 2007 & Estados Unidos & Unidade Própria \\
\hline Vestuário & 2007 & Venezuela & Franqueado Direto \\
\hline Alimentação & 2008 & Paraguai & Franqueado Direto \\
\hline Alimentação & 2009 & Angola & Franqueado Direto \\
\hline Alimentação & 2009 & Paraguai & Franqueado Direto \\
\hline Serviços & 2009 & Japão & Franqueado Direto \\
\hline Educação & 2010 & Estados Unidos & Franqueado Direto \\
\hline Serviços & 2010 & Panamá & Franqueado Direto \\
\hline Serviços & 2010 & Estados Unidos & Franqueado Direto \\
\hline Alimentação & 2011 & Estados Unidos & Unidade Própria \\
\hline & & & \\
\hline
\end{tabular}

Fonte: Elaborado pelos autores.

Em sua pesquisa em 2012, Rocha et al. (2012) já haviam identificado os Estados Unidos como um dos grandes destinos das franquias brasileiras, o segundo país mais procurado, perdendo apenas para Portugal em número total de marcas instaladas. 


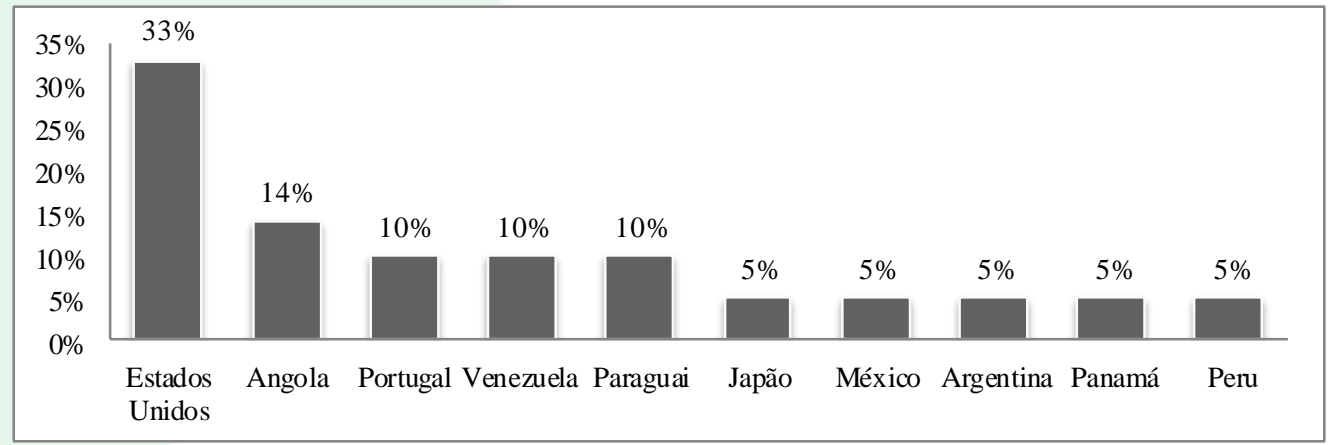

Figura 4 - Primeiro país onde a rede se instalou Fonte: Elaborado pelos autores.

Outras dez marcas, excluindo-se as que se estabeleceram em Angola, consolidaram sua internacionalização em países geograficamente ou culturalmente próximos. Considere que entre os 10 países de destino, em oito deles predomina o idioma português ou espanhol. Exceção apenas para os Estados Unidos e o Japão.

Em estudos realizados por Welsh e Alon (2001) e Alon e Welsh (2001) que argumentaram que o modo de entrada das franquias no exterior estava diretamente ligado à distância cultural, tal proposição não foi passível de comprovação devido ao baixo número da amostra no âmbito desta pesquisa, não há como comprovar a aderência deste argumento. O que se observa na amostra de empresas que foram entrevistadas, é a ausência de indícios que reforcem a relação entre país e método de entrada. Como exemplo, o modo de entrada de empresas brasileiras no mercado norte-americano ocorreu em decorrência de uma pluralidade de métodos utilizados: máster franquias, unidades próprias e franqueados diretos.

Os países que também possuem mais de uma operação dentro das redes pesquisadas, Angola e Portugal, também apresentam métodos de entrada distinto em seus casos.
O Japão, que foi o país escolhido como destino de uma rede de serviços de forma a atender os decasséguis brasileiros, termo japonês que designa qualquer pessoa que deixa sua terra natal para trabalhar, temporariamente, em outra região, optou por franquear suas atividades diretas do Brasil apesar da distância cultural em relação a este país.

A Figura 5 mostra que a evolução no método de entrada das franquias brasileiras se alterou com o tempo. À medida que o franchising nacional se consolidou e despertou interesse em ser exportado para outros países, principalmente pela ação de terceiros interessados, o que corrobora com a afirmação de Mendelsohn (1994), ocorreu uma mudança de postura, ou seja, das opções estratégicas para a internacionalização.

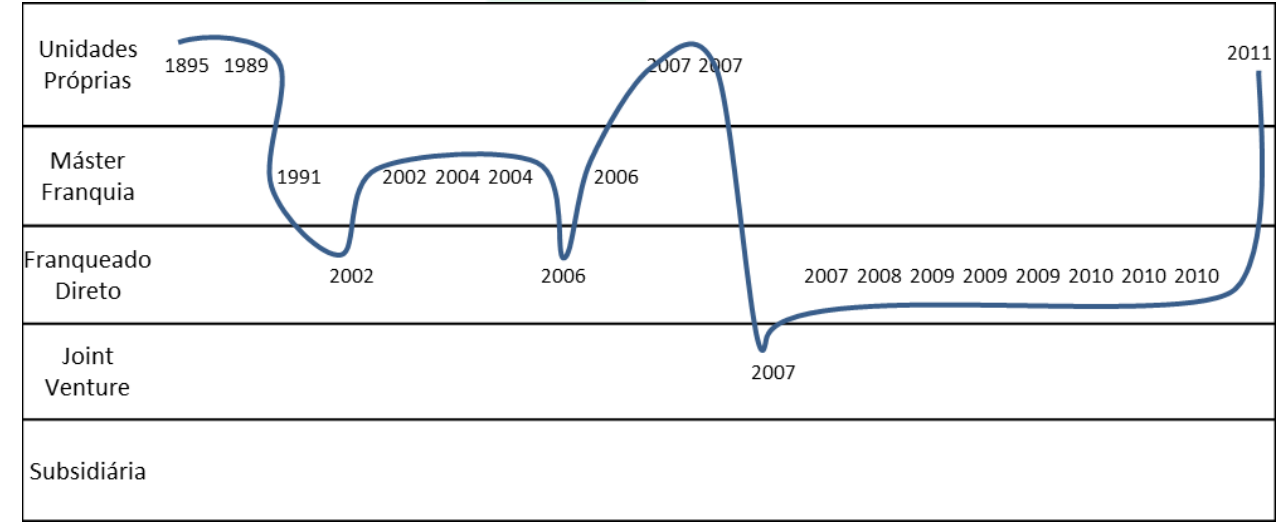

Figura 5 - Evolução do modo de entrada Fonte: Elaborado pelos autores. 
Considere que a primeira vez que uma rede foi procurada com o intuito de ser levada para outro país foi exatamente em 2002. Após esse ano houve uma alternância em redes procuradas e não procuradas até 2008. Com exceção de uma, todas as redes que se internacionalizaram a partir desse ano foram procuradas por agentes externos com o desejo de levar a marca e seus processos para outros países. A Tabela 3 mostra exatamente que todas as redes que franquearam suas atividades diretas do Brasil foram procuradas por agentes externos à rede de franquias. $\mathrm{O}$ que se observa é que não se tratava de uma opção estratégica para a franquia se internacionalizar. Entretanto, a procura por parte de um franqueador externo despertou esse interesse no empresário brasileiro, fato que fez com que muitas redes dessem início a seu processo de internacionalização.

Tabela 3 - Relação entre método de entrada e procura por agente externo

\begin{tabular}{|l|c|c|}
\hline \multicolumn{1}{|c|}{ MÉTODO DE ENTRADA } & $\begin{array}{c}\text { REPRESENTATIVIDADE NA } \\
\text { AMOSTRA }\end{array}$ & $\begin{array}{c}\text { FOI PROCURADO PARA LEVAR SUA } \\
\text { MARCA PARA O EXTERIOR }\end{array}$ \\
\hline Franqueado direto & $48 \%$ & $100 \%$ \\
\hline Máster franquia & $24 \%$ & $80 \%$ \\
\hline Unidades próprias & $24 \%$ & $0 \%$ \\
\hline Joint venture & $5 \%$ & $100 \%$ \\
\hline
\end{tabular}

Fonte: Elaborado pelos autores.

Outro ponto a destacar, que pode ser evidenciado na Tabela 3, é que as empresas que optaram por abrir Unidades Próprias não foram procuradas; o processo se deu devido a um posicionamento interno da empresa. Essas empresas contaram com um maior controle de seus negócios e usaram a primeira unidade como teste para a expansão internacional. Conceitos e serviços foram testados e adaptados.

Um dado que reforça este tipo de posicionamento são as barreiras encontradas pelas franquias quando decidiram ir para o exterior. Observase que estas franquias brasileiras, da amostra, na sua primeira investida em território internacional, não consideraram recursos financeiros para optar por um método de entrada. Os métodos de entrada, como abordados anteriormente, podem estar relacionados à maneira que a rede procede em razão de sua capacidade financeira, assim esse não foi fator decisivo no processo de escolha.

Apenas uma empresa contratou especialistas para conduzir o trabalho de tradução de seus manuais de operação, o que representa mais um fator que corrobora o argumento de que os agentes externos foram essenciais nesse processo, trazendo recursos e expertise. Estudo conduzido por Borini, Ribeiro, Coelho \& Proença (2006) constatou que possuir pessoal com experiência internacional seria um fator que aumentaria a possibilidade de explorar mercados internacionais.

Tabela 4 - Barreiras para abertura da primeira unidade em relação ao novo mercado

\begin{tabular}{|l|l|l|}
\hline \multicolumn{1}{|c|}{ SETOR } & \multicolumn{1}{|c|}{ NÚMEROS } & \multicolumn{1}{c|}{ PRINCIPAL BARREIRA } \\
\hline Educação & Seis empresas, 28,5\% & $\begin{array}{l}\text { Treinamento das equipes, Experiência dos } \\
\text { gestores e Leis/ Burocracia. }\end{array}$ \\
\hline Alimentação & Cinco empresas, 23,8\% & $\begin{array}{l}\text { Falta de conhecimento da cultura e Leis/ } \\
\text { Burocracia. }\end{array}$ \\
\hline Serviços & Cinco empresas, 23,8\% & Leis/ Burocracia \\
\hline Vestuário & Três empresas, 14,3\% & Falta de conhecimento da cultura \\
\hline Acessórios & Duas empresas, 9,5\% & $\begin{array}{l}\text { Falta de conhecimento da cultura, } \\
\text { Experiência dos gestores e Leis/ Burocracia. }\end{array}$ \\
\hline
\end{tabular}

Fonte: Elaborado pelos autores. 
Uma questão que se coloca é: se na primeira investida ao exterior não houve uma motivação interna da organização, com um planejamento estruturado e estratégico visando a expansão internacional, haja visto que as empresas foram procuradas por agentes externos, como foi a continuidade deste processo? As franquias continuaram a se internacionalizar? Continuaram a ser procuradas por agentes externos a elas? Em resposta a estas indagações observa-se que na estratégia atual destas empresas, após a primeira unidade de negócios no exterior, que elas adotam o sistema de Franqueado Direto ou passaram a implementar subsidiária própria que vende e administra as novas franquias nos países de destino. A Figura 5 mostra a atual estratégia evidenciada em 2012 pelas empresas da amostra nos mercados internacionais.

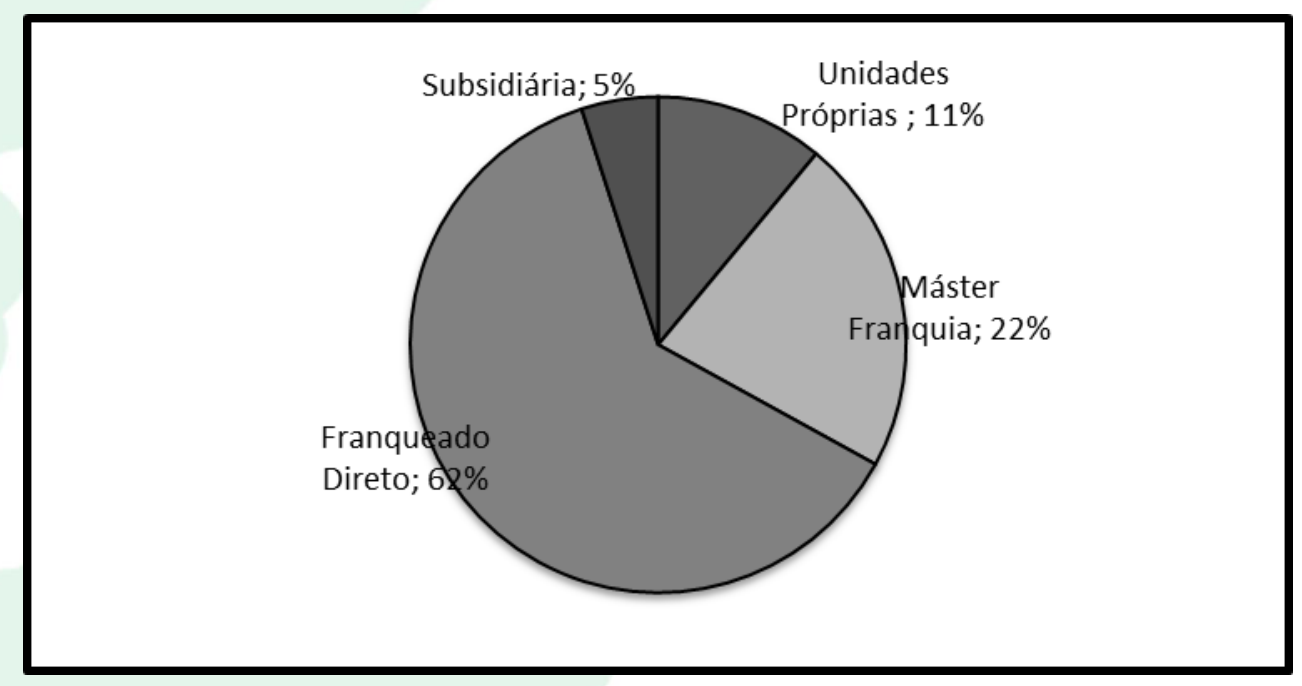

Figura 6 - Método de entrada atual das redes pesquisadas em 2012 Fonte: Elaborado pelos autores.

\section{CONCLUSÕES E RECOMENDAÇÕES}

Este artigo teve como finalidade investigar, de forma descritiva, os métodos de entrada que as franquias brasileiras utilizaram quando iniciaram seu processo de internacionalização. $O$ momento de florescimento econômico no mercado interno acabou por alterar as expectativas empresariais em relação as janelas de oportunidades comerciais que poderiam se abrir em mercados internacionais. O que encorajou o processo de internacionalização por parte das redes de franquias brasileiras foi a iniciativa de um agente externo da organização. Quanto a pergunta de pesquisa inicial deste artigo, o principal método empregado quando iniciaram a internacionalização de suas atividades, a escolha do sistema de franquear o negócio direto do Brasil foi a mais encontrada na amostra.

$\mathrm{O}$ fato de o mercado doméstico ainda não estar totalmente desenvolvido com perspectivas claras de crescimento interno, teve uma forte influência no método de entrada no exterior. Franquear seu negócio diretamente do Brasil, não por falta de recursos como na teoria de escassez de recursos, mas sim por não ser a prioridade, foi o principal método empregado quando as redes iniciaram a internacionalização nos últimos anos.

Outro ponto a destacar neste estudo é a vocação bastante frágil para a internacionalização entre as redes de franquias brasileiras; e salvo poucas exceções, a internacionalização apenas ocorre quanto tais empresas são procuradas por terceiros. Aproveitar o ciclo de dinamismo econômico que o franchising brasileiro vive é primordial, e como um ponto positivo pode-se salientar que a partir de 2008 as franquias brasileiras despertaram um interesse maior em investidores interessados em levar seus conceitos e produtos para outros países. Esse processo, sem dúvida, impulsionou a internacionalização destas redes e contribuiu para a rápida disseminação de unidades franqueadas brasileiras pelo mundo. Franquear a rede a partir do Brasil só foi possível graças a essa procura pelo agente externo, o que fez com que esse sistema fosse o mais escolhido pelas redes entrevistadas desde 2008.

O desempenho do ramo de franquias no Brasil contraria a percepção geral de que o Brasil é um exportador apenas de commodities. Os setores franqueados são os mais variados. Um particular exemplo da força das empresas de franchising brasileiras são as redes de educação analisadas nesta pesquisa que, juntas, possuem 180 unidades operando em uma diversidade de países.

As redes estudadas, na sua grande maioria, desconheciam os projetos governamentais de promoção 
Redes de Franquia Brasileiras Internacionalizadas: Evolução do Método de Entrada no Exterior

à internacionalização promovida pela Apex-Brasil. Apenas duas empresas recorreram a estas linhas de incentivos e, para ambas, a avaliação foi positiva. Julgaram que a qualidade do serviço e a ajuda foram excelentes, o que significa que se todos conhecessem esses dispositivos, a internacionalização talvez tivesse se dado anteriormente e tal expansão ganhasse uma maior velocidade. É primordial que todos os mecanismos governamentais sejam conhecidos para que as empresas possam usufruir dos dispositivos e das possibilidades oferecidas.

Em relação ao ramo das franquias, esta pesquisa sugere ser necessário empreender esforços no sentido de promover a empresa no exterior antes de qualquer investida rumo à internacionalização. Esta iniciativa tende a oferecer elementos para que a franquia possa, no futuro, escolher o parceiro e o método de entrada que venham a ser mais convenientes para a empresa. Seria uma iniciativa muito mais proativa que contraria a postura observada na maioria das redes que se internacionalizaram, de certa forma passiva, ao simplesmente aceitarem a oferta de agentes externos para implementar unidades de franquias no exterior.

Da perspectiva da academia, este trabalho buscou contribuir com um conhecimento mais apurado sobre os principais métodos de internacionalização de franquias nos países emergentes. Diferente dos pressupostos defendidos pela teoria da escassez de recursos, a internacionalização não se deu pela falta de recursos, todas as redes pesquisadas possuíam recursos próprios e não necessitavam, à época da internacionalização, de um parceiro para acessar recursos de ordem financeira.

Esse achado sugere novas pesquisas longitudinais acerca de métodos utilizados para a internacionalização de redes de franquias de países desenvolvidos, assim como devem ser investigados os eventuais padrões de diferenciação em relação a redes de países emergentes. Por fim, sugere-se que estudos futuros ampliem a amostra de empresas franquiadas internacionalizadas, com a utilização de métodos de pesquisa quantitativos que venham a validar (ou não) os resultados aqui apresentados, pautados em uma abordagem exploratória e qualitativa. Assim, seria possível comprovar a validade da diretriz teórica da pesquisa e apontar os principais fatores motivadores da utilização de métodos de entrada na internacionalização de franquias brasileiras.

\section{REFERÊNCIAS}

ABF. Associação Brasileira de Franchising (2012): Evolução do setor. Recuperado em: 19 de julho de 2014, de <http://www.portaldofranchising.com.br/site/conten t/interna/index.asp? $\operatorname{cod} \mathrm{A}=11 \& \operatorname{cod} \mathrm{C}=4$ \&origem $=\mathrm{so}$ breosetor>.
ABF. Associação Brasileira de Franchising (2013) Evolução do setor 2002-2013. Recuperado em: 14 de março de 2014, de: <http://www.portaldofranchising.com.br/site/conten t/interna/index.asp?LarguraTela $=1366 \& \operatorname{cod} A=11 \&$ codC $=15$ \&origem $=$ sobreosetor $>$.

Aguiar H. S. (2014) Internacionalização de franquias brasileiras: o processo de internacionalização conduzida. Centro Universitário da FEI. São Paulo, SP, Brasil.

Alon, I. (2001) The Use of Franchising by US-Based Retailers. Journal of Small Business Management, 39(2), 111-122

Alon, I. (2006) Market conditions favoring master international franchising. Multinational Business Review, 14(2), 67-82.

Alon, I., Welsh, D. H. (2001) International franchising in emerging markets: China, India, and other Asian countries. Chicago: Cch Inc.

Barkema, H. G., Vermeulen, F. (1998) International expansion through start-up or acquisition: a learning perspective. Academy of Management journal, 41(1), 7-26.

Benoun, M., Héliès-Hassid, M. (2004) Category management, mythes et réalités. Revue Française du Marketing, 198 (3/5), 73-86.

Borini, F. M., Ribeiro, F. C. F., Coelho, F. P., Proença, E. R. (2006) O prisma da internacionalização: um estudo de caso. Revista de Administração FACES Journal, 5(3), 42-55.

Borini, F., Rocha, T., Spers, E. (2012) Desafios para a internacionalização das franquias brasileiras: um survey com franquias internacionalizadas. In: Melo, P.R.L., Andreassi, T. (Org.) Franquias brasileiras. (pp. 71-87) São Paulo: Cengage.

Burton, F. N., Cross, A. R. (1995) Franchising and foreign market entry. International marketing reader, 35-48.

Carney, M., \& Gedajlovic, E. (1991) Vertical integration in franchise systems: agency theory and resource explanations. Strategic Management Journal, 12(8), 607-629.

Chang, S. J., Rosenzweig, P. M. (2001) The choice of entry mode in sequential foreign direct investment. Strategic Management Journal, 22(8), 747-776.

Coelho, D. B. (2011) Novas reflexões sobre a internacionalização das empresas brasileiras. 
Revista de Administração de Empresas. 51(4), 411412.

Combs, J. G., Ketchen, D. J. (1999) Can capital scarcity help agency theory explain franchising? Revisiting the capital scarcity hypothesis. Academy of Management Journal, 42(2), 196-207.

Combs, J. G., Ketchen, D. J., Shook, C. L., Short, J. C. (2011) Antecedents and consequences of franchising: Past accomplishments and future challenges. Journal of Management, 37(1), 99-126.

Dahab, S. (1996). Entendendo franchising: uma alternativa eficaz para o pequeno e médio empreendedor, Salvador: Casa da Qualidade.

Doherty, A. M., Alexander, N. (2004) Relationship development in international retail franchising: case study evidence from the UK fashion sector. European Journal of Marketing, 38(9/10), 12151235.

FDC. Fundação Dom Cabral (2012) Ranking das transnacionais_brasileiras 2012. Recuperado em: 3 de dezembro de 2014, de: <http://www.fdc.org.br/pt/Documents/2012/ranking _transnacionais_brasileiras2012.pdf $>$.

Gibbs, G. (2009) Análise de dados qualitativos: coleção pesquisa qualitativa. São Paulo: Bookman.

Hoy, F., Shane, S. (1998) Franchising as an entrepreneurial venture form. Journal of Business Venturing, 13(2), 91-94.

Jensen, M. C., \& Meckling, W. H. (1976) Theory of the firm: managerial behavior, agency costs and ownership structure. Journal of financial economics, 3(4), 305-360.

Kedia, B. L., Ackerman, D. J., Justis, R. T. (1995) Changing barriers to the internationalization of franchising operations: perceptions of domestic and international franchisors. The International Executive, 37(4), 329-348.

Khauaja, D. (2009) Gestão de marcas na estratégia de internacionalização de empresas: estudo com franqueadoras brasileiras. Tese de doutorado, Universidade de São Paulo, São Paulo, SP, Brasil.

Marques, D. S. P., Merlo, E. M., \& Lucchesi, C. A. M. (2005) Os motivos envolvidos na internacionalização de franquias brasileiras. FACEF Pesquisa-Desenvolvimento e Gestão, 8(2).

Marques. D. S. P. (2006) Internacionalização de franquias: um mapeamento sobre a presença de redes brasileiras no exterior. Dissertação de mestrado. Universidade de São Paulo, Ribeirão Preto, SP, Brasil.

Melo, P. L. R. (2012) Internacionalização das redes de franquias brasileiras: uma análise organizacional e institucional. Tese de doutorado. Universidade de São Paulo, São Paulo, SP, Brasil.

Melo P.L.R., Andreassi T. (Org.). (2012) Franquias brasileiras: estratégia, empreendedorismo, inovação e internacionalização. São Paulo: Cengage Learning.

Melo, P. L. de R., Andreassi, Tales, Oliveira Jr., M. M. (2010) Fusão e internacionalização de empresas brasileiras: o caso trendfoods e China in Box. Revista Inovação, Gestão e Produção, 2(9), 13-24.

Mendelsohn, M. (1994) A essência do franchising. São Paulo: Difusão Educação e Cultura.

Oliveira Jr., M.M. (2010) Multinacionais brasileiras: internacionalização, inovação e estratégia global. São Paulo: Bookman.

Oxenfeldt, A. R., \& Kelly, A. O. (1969) Will successful franchise systems ultimately become wholly-owned chains. Journal of Retailing, 44(4), 69-83.

Pedro, I., Filipe, J. A., \& Reis, E. (2008) Factores determinantes da internacionalização das redes de «franchising» ibéricas. Economia Global e Gestão, 13(1), 65-84.

Petersen, B., Welch, L. S. (2002) Foreign operation mode combinations and internationalization. Journal of Business Research, 55(2), 157-162.

Quinn, B. (1998) Towards a framework for the study of franchising as an operating mode for international retail companies. The International Review of Retail, Distribution and Consumer Research, 8(4), 445-467.

Quinn, B., Doherty, A. M. (2000) Power and control in international retail franchising-evidence from theory and practice. International marketing review, 17(4/5), 354-372.

Quinn, B., Alexander, N. (2002) International retail franchising: a conceptual framework. International journal of retail \& distribution management, 30(5), 264-276.

Randall, G. (1994) Trade marketing strategies: the partnership between manufacturers, brands and retailers. Oxford, UK: Butterworth-Heinemann. 
Rocha, T., Borini, F., Spers, E. (2010) Processos e barreiras para internacionalização de franquias brasileiras. Relatório para a ABF. São Paulo: ABF.

Rocha, T.V., Borini F.M., Spers E.E., Khauaja D., Camargo A. (2012) Aspectos mercadológicos e estratégicos da internacionalização das franquias brasileiras. São Paulo: ESPM.

Sanghavi, N. (1991) Retail franchising as a growth strategy for the 1990s. International Journal of Retail \& Distribution Management, 19(2).

Sardy, M., Alon, I. (2007) Exploring the differences between franchisee entrepreneurs and nascent entrepreneurs. International Entrepreneurship and Management Journal, 3(4), 403-418.

Sashi, C. M., Karuppur, D. P. (2002) Franchising in global markets: towards a conceptual framework. International Marketing Review, 19(5), 499-524.

Silva, C. E. V., Mendes, D. A. P.; Gomes, J. S. (2002) O controle gerencial na internacionalização de franquias: o caso de uma empresa brasileira. Anais ...Congresso da USP de Controladoria e Contabilidade. São Paulo, SP, Brasil, Outubro.

Stanworth, J., Dandridge, T. (1994) Business franchising and economic change: an overview. International Small Business Journal, 12(2), 12-14.
Stanworth, J., Stanworth, C., Watson, A., Purdy, D., \& Healeas, S. (2004) Franchising as a small business growth strategy a resource-based view of organizational development. International Small Business Journal, 22(6), 539-559.

Toledo, G. L., Proença, C. (2005) Fatores críticos de sucesso na franquia: uma análise sob a óptica de exfranqueados no município de São Paulo. Caderno de Pesquisas em Administração, São Paulo, 12(1), 43-53.

Welch, L. S. (1989) Diffusion of franchise system use in international operations. International Marketing Review, 6(5), 7.

Welsh, D., Alon, I. (2001) International franchising in emerging markets: central and Eastem Europe and Latin America. Chicago: CCH Inc.

Welsh, D. H., Alon, I., Falbe, C. M. (2006) An examination of international retail franchising in emerging markets. Journal of Small Business Management, 44(1), 130-149.

WFC, World Franchise Council. (2012) Country profile. Recuperado em: 2 de Agosto de 2013, de: <http://www.worldfranchisecouncil.org/control/cpv iew? contentId=WFC_HOME $>$ Acesso em 2 de agosto. 